\title{
Quantification of urban structure on building block level utilizing multisensoral remote sensing data
}

\author{
Michael Wurm ${ }^{* a, b}$, Hannes Taubenböck ${ }^{\mathrm{a}}$, Stefan Dech ${ }^{\mathrm{a}, \mathrm{b}}$ \\ ${ }^{\mathrm{a}}$ German Remote Sensing Data Center (DFD), German Aerospace Center (DLR), Oberpfaffenhofen, \\ 82234 Wessling, Germany \\ bulius-Maximilians University Würzburg, Geographical Institute, Earth Observation, 97074 \\ Würzburg, Germany
}

\begin{abstract}
Dynamics of urban environments are a challenge to a sustainable development. Urban areas promise wealth, realization of individual dreams and power. Hence, many cities are characterized by a population growth as well as physical development. Traditional, visual mapping and updating of urban structure information of cities is a very laborious and cost-intensive task, especially for large urban areas. For this purpose, we developed a workflow for the extraction of the relevant information by means of object-based image classification. In this manner, multisensoral remote sensing data has been analyzed in terms of very high resolution optical satellite imagery together with height information by a digital surface model to retrieve a detailed 3D city model with the relevant land-use / land-cover information. This information has been aggregated on the level of the building block to describe the urban structure by physical indicators. A comparison between the indicators derived by the classification and a reference classification has been accomplished to show the correlation between the individual indicators and a reference classification of urban structure types. The indicators have been used to apply a cluster analysis to group the individual blocks into similar clusters.
\end{abstract}

Keywords: urban structure, land-use land-cover, VHR, object-based, DSM

\section{INTRODUCTION}

\subsection{Background and aim of the study}

The city is the main human habitat and has evolved under the influence of its most creative resident - the human being over many years until it has reached its today's various kinds of sizes, shapes and powers all over the world. Even though they all share basic similarities, all cities were created individually and all have their individual history which makes every city a unique, stone-made urban ecosystem. Creation of these ecosystems, resulting in their today's shapes, is a process over time as a result of political, economic, ecological, cultural and social influences, technical developments or military conflicts [1]. Next to that, tremendous urban population growth over the last decades has led to global urban population equaling rural population for the first time in history in 2008 [2] resulting in constant spatial expansion and re-densification of cities.

A sustainable governance of a city is based on valuable, reliable, up-to-date and area-wide information of the urban area. By means of remote sensing, a fast and efficient tool for providing this information is at disposal for acquisition and mapping of the urban spatial structure from above. In that way, earth observation aids decision-making and the development of new strategies with the deployment of detailed and accurate data [3]. Latest developments in remote sensing technology, especially with space-borne sensors, have helped to provide more actual, detailed, accurate and costefficient tools to map urban areas at a resolution of better than one meter. Commercial providers of satellite imagery make it possible to identify individual urban elements in the small-structured urban landscape by means of latest multispectral satellites such as IKONOS, QuickBird, GeoEye-1 or WorldView-2 at high geometrical, spectral and temporal resolution [4]. 
However, utilization of such geometrically detailed data arises problems in automated access to the information stored in these images. Together with the development of third generation earth observation satellites, image interpretation techniques have been modified to the new challenges. Especially in urban environments, adapted strategies in image classification have been sought to confront the problem of low image classification accuracies due to similar spectral signatures of urban objects [5]. In this sense, multi-source information is implemented in the analysis of remotely sensed data of urban areas by means of image information fusion to retrieve detailed information about the urban structure.

In this study we show the relationship between quantifiable physical structural and pattern indicators derived by means of automatic information extraction from remotely sensed information and urban structure type information derived by visual inspection and classification of multi-source information of Munich, Germany [6].

Specifically we address several questions:

- Which physical indicators can be derived from multisensoral remote sensing data for urban structure analysis?

- Do these indicators show significant differences for different urban structure types?

- Is it possible to automatically classify urban structure types on the basis of automatic image classification?

\subsection{The concept of urban structure type classification in Germany}

The urban ecosystem has developed over many years with the result of a large diversity of urban subcomponents, which characterize in their entirety the individual urban ecosystem. The identification of these heterogeneous units serves as a basis for an ecological-sustainable urban planning [7]. The latter is in need for a breakdown of the entire city into spatially homogeneous regions instead of artificial administrative units. To achieve this goal, urban land-use and urban structure types have been defined to subdivide and represent the particular municipality [8]. The urban structure types (UST) approach allows the integration of different technical, methodological and spatial approaches to urban environments to a common spatial working basis [9], [10]. Major indicators for the discrimination of individual structure types are related to structural properties of the contained built-up physiognomy [11]. [12] defined various criteria representing similar areal types. This concept aims at the possibility to

a) aggregate the individual classes to superordinate classes,

b) spatial transferability of the results and

c) integration into existing planning processes.

Whilst the term urban structure types was only created decades later, its methodology has developed already in the 1960's in works about the structuring of the urban landscape into homogeneous landscape units [13]. Later on, research about the urban ecosystem in terms of biotope mapping became more important towards landscape ecology. For Munich, [12] presented a pilot study for an ecological differentiated consideration of a large study area. They implemented physiognomic characteristics of the urban fabric as well as climatic, hydrological attributes and heat demand. However, besides Munich, various other German cities have developed and accomplished similar urban structure types or urban biotope classifications. Leipzig updated its first map from 1994 in 2000 with 78 and 47 classes respectively [10]. Besides color infrared (CIR) aerial photographs, panchromatic SPOT satellite imagery (1994) and IRS-1C (1998) imagery have been utilized to differentiate the individual classes based on: utilization, building type, building structure, built-up density, vegetation fraction and fraction of impervious surfaces to finally extract 25 different urban structure types. A similar work has been accomplished for the city of Dresden by means of visual image interpretation of aerial photographs and terrestrial investigation [8]. Altogether, 20 structure types with special consideration of five built-up types have been produced. However, the precedent method has the disadvantage of high personnel and temporal expenses and thus with a low up-dating rate of the maps. For the city of Halle, 29 urban structure types with eight builtup structure types have been developed and classified by means of CIR aerial photograph interpretation in 1995 [14]. In Berlin, a first classification of urban structure types was presented in 1995 on the basis of CIR aerial photographs and updated in the years 2002, 2005 and 2008 [15]. Summing up, the concept of urban structure types has been adopted by various cities in Germany. However, various kinds of initial data for the classification and subjective, individual, mostly visual interpretation caused various, individual numbers and types of classes. While the thematic attribute for the discrimination of the urban structure types is usually the utilization of the area, the spatial extension is mostly defined as the building block. For this unit, various sources of information were usually utilized for the discrimination of the 
distinct structure type: terrestrial survey, remote sensing data (satellite imagery or aerial photographs), land-use classifications etc. These data sets usually form the basis to describe the individual urban structure elements within each individual building block. This work was mostly done by means of traditional, visual image interpretation and transferred into a geographic information system (GIS). However, new sensor and data types have favored new techniques of image interpretation. A semiautomatic object-based method was applied for an update and monitoring of the classification for Leipzig [9] analyzing spectral as well as texture parameters. Airborne hyperspectral data were analyzed by [16] to identify distinct surface materials and classified together with height information by a normalized digital surface model (nDSM) for the classification of biotopes utilizing shape and size parameters.

\subsection{Study area and data sets}

The test site of the presented study is the city of Munich, Germany. It is the capital of the southernmost German federal state of Bavaria and is an important economic and cultural center for the eastern alpine region. Munich is home to 1.3 million inhabitants, making it Germany's third largest city with an area of $310 \mathrm{~km}^{2}$. The city is split by the Isar river and has played an important role throughout history. Large parts of the city, among them the historic center, have been destroyed during World War II, but were mostly restored again afterwards. A prominent part of the urban environment is the 'Englischer Garten' with its $4.17 \mathrm{~km}^{2}$ making it the seventh largest urban park in the world.

The basis for the comparison of the urban structure between automatically derived information by means of remote sensing and a reference urban structure type classification for the city of Munich is a land-use / land-cover (LULC) classification. For the detailed characterisation of the urban landscape we utilized very high resolution (VHR) optical satellite imagery as well as a photogrammetric DSM from HRSC-AX (High Resolution Stereo Camera - Airborne Extended). The satellite imagery was acquired by the sensor IKONOS with a spectral resolution of four bands and an additional panchromatic band and a geometric resolution of $3.28 \mathrm{~m}$ and $0.82 \mathrm{~m}$ respectively [17]. However, upon delivery, the data was radiometrically corrected and pan-sharpened to a geometric resolution of one meter. The height information was implemented in terms of a digital surface model which was derived by the HRSC-AX which was initially developed and constructed at DLR for the Russian Mars96 mission and later on modified for airborne application. A GPS/INS (Global Positioning System / Inertial Navigation System) is integrated in the camera for the processing of the data sets to digital surface models and orthoimages [18]. The utilized data as well as the urban structure types classification (UST) for the city of Munich are displayed in figure 1. The class hierarchy for the UST classification is presented in table 1, however the class names of the most detailed level are only displayed for the various housing and industrial built-up constructions.

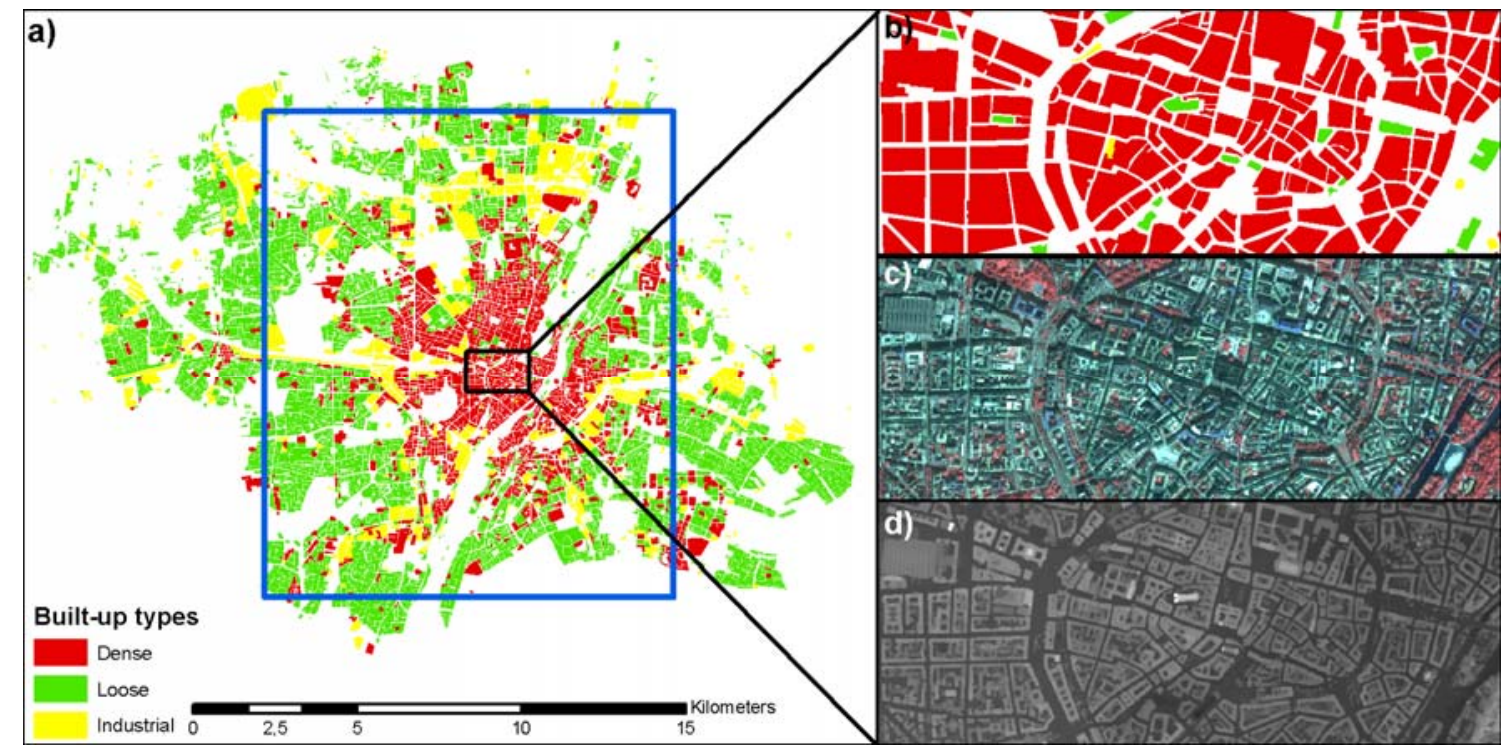

Figure 1. Spatial extension of the entire urban structure type classification of Munich displaying built-up blocks aggregated on three structural types; study area (blue rectangle) and magnification of the various data types, b) UST, c) IKONOS false color composite 4/3/2 and d) DSM. 
Table 1. Class hierarchy for the urban structure types classification of Munich.

\begin{tabular}{|c|c|c|c|c|}
\hline & & & Surface water & \multirow{24}{*}{ City } \\
\hline & \multicolumn{2}{|c|}{ Agricultural areas } & \multirow{3}{*}{ Green areas } & \\
\hline & \multicolumn{2}{|c|}{ Green areas } & & \\
\hline & \multicolumn{2}{|c|}{ Woods and hedgerows } & & \\
\hline Small multi-storey buildings & \multirow{5}{*}{ Dense built-up } & \multirow{14}{*}{$\begin{array}{l}\text { Housing } \\
\text { construction }\end{array}$} & \multirow{20}{*}{ Built-up areas } & \\
\hline Large multi-storey buildings & & & & \\
\hline Perimeter block development & & & & \\
\hline Dense block development & & & & \\
\hline Mix of various multi-storey buildings & & & & \\
\hline Small semi-detached houses & \multirow{9}{*}{ Loose built-up } & & & \\
\hline Detached and semi-detached houses & & & & \\
\hline Row house development & & & & \\
\hline Small, freestanding multi-storey buildings & & & & \\
\hline Regular block development & & & & \\
\hline Row of houses linked together & & & & \\
\hline Highrise buildings & & & & \\
\hline Old towns & & & & \\
\hline Mixed use area & & & & \\
\hline Large hall buildings & \multirow{5}{*}{\multicolumn{2}{|c|}{ Industrial built-up }} & & \\
\hline Small hall buildings & & & & \\
\hline Special structures & & & & \\
\hline $\begin{array}{l}\text { Mixed developments: small multi-storey \& hall } \\
\text { buildings }\end{array}$ & & & & \\
\hline $\begin{array}{l}\text { Mixed developments: large multi-storey \& hall } \\
\text { buildings }\end{array}$ & & & & \\
\hline & Traf & & & \\
\hline
\end{tabular}

\section{METHODOLOGY - DERIVATION OF LULC CLASSIFICATION}

The aim of the presented study is a comparative analysis of automatic information extraction from remote sensing imagery with manual interpretation of aerial photographs in terms of urban structure types. First, the relevant information has to be extracted from the multisensoral remotely sensed data. In general, an object-based framework has been applied on the two data sets VHR optical satellite imagery and the DSM for a detailed description of the urban landscape. The process is structured into image segmentation and image classification.

\subsection{Image information extraction}

The method for the extraction of the relevant information in terms of LULC classification is described by [20] and is here roughly summarized. Data preprocessing has been done applying geometric and atmospheric correction to the satellite image. As the geometric accuracy of the DSM due to on-board GPS/INS systems is considered to be higher than the map projected but not orthorectified IKONOS image, the first-mentioned data set has been assigned as the geometric 
master file. Latter was orthorectified using digital aerial orthoimages as a spatial reference for ground control points measurement.

The first image analysis step focuses on the extraction of building footprints by means of image segmentation and objectbased image classification of the DSM. To achieve this goal, the geometry of the UST classification in terms of the outlines of the individual building block boundaries has been integrated into the workflow. For each of the building blocks, segmentation has been applied to generate 'real world' image objects representing individual buildings for each block. Based on shape, neighborhood and height parameters, the objects are classified as 'buildings'. For each of the buildings it is possible to retrieve the relative height information as a relationship between the absolute height of the building object and the surrounding area.

The result of this processing step is a 'building mask' representing individual building objects including their heights. This building mask is integrated into the second analysis step where the optical data are first segmented into image objects by means of an image segmentation optimization workflow developed by [21] and then classified within a similar workflow presented by [22]. Additionally, ancillary data have been integrated into the workflow in terms of imported information about 'streets' from the OpenStreetmap project.

\subsection{Results and accuracy assessment}

The result of the combined analysis of spectral information and height information is a detailed LULC classification of the covered area of Munich. Figure 2 shows a subset of the classification result for the city center of Munich with the classes 'buildings', 'bare soil', grassland/meadow', 'impervious surfaces', 'streets', trees/shrubs' and 'surface water'. Clearly, some relevant structural patterns of the city may be identified like the historical center in the center of the image, the urban green areas with its large 'Englischer Garten' in the northeast of the center, the Isar river as a blue band and large impervious areas heading west from the main train station and the fair ground in the southwest.

An accuracy assessment was done on the results by means of visual inspection of 200 randomly generated points for each of the distinct LULC classes. The results of the assessment are shown in Table 2 and show an overall accuracy of the classification of $93.93 \%$.

Table 2. Accuracy assessment of the LULC classification of Munich.

\begin{tabular}{|l|c|c|}
\hline & \multicolumn{2}{|c|}{ Munich } \\
\hline Classes & User Acc. [\%] & Prod. Acc. [\%] \\
\hline Buildings & 98.46 & 96.00 \\
\hline Bare soil & 89.66 & 91.00 \\
\hline Trees/shrubs & 92.96 & 92.50 \\
\hline Grassland/meadow & 93.62 & 95.50 \\
\hline Sealed & 86.45 & 92.50 \\
\hline Streets & 99.48 & 96.00 \\
\hline Surface water & 97.92 & 94.00 \\
\hline Total & \multicolumn{2}{|c|}{$\mathbf{9 3 . 9 3}$} \\
\hline
\end{tabular}




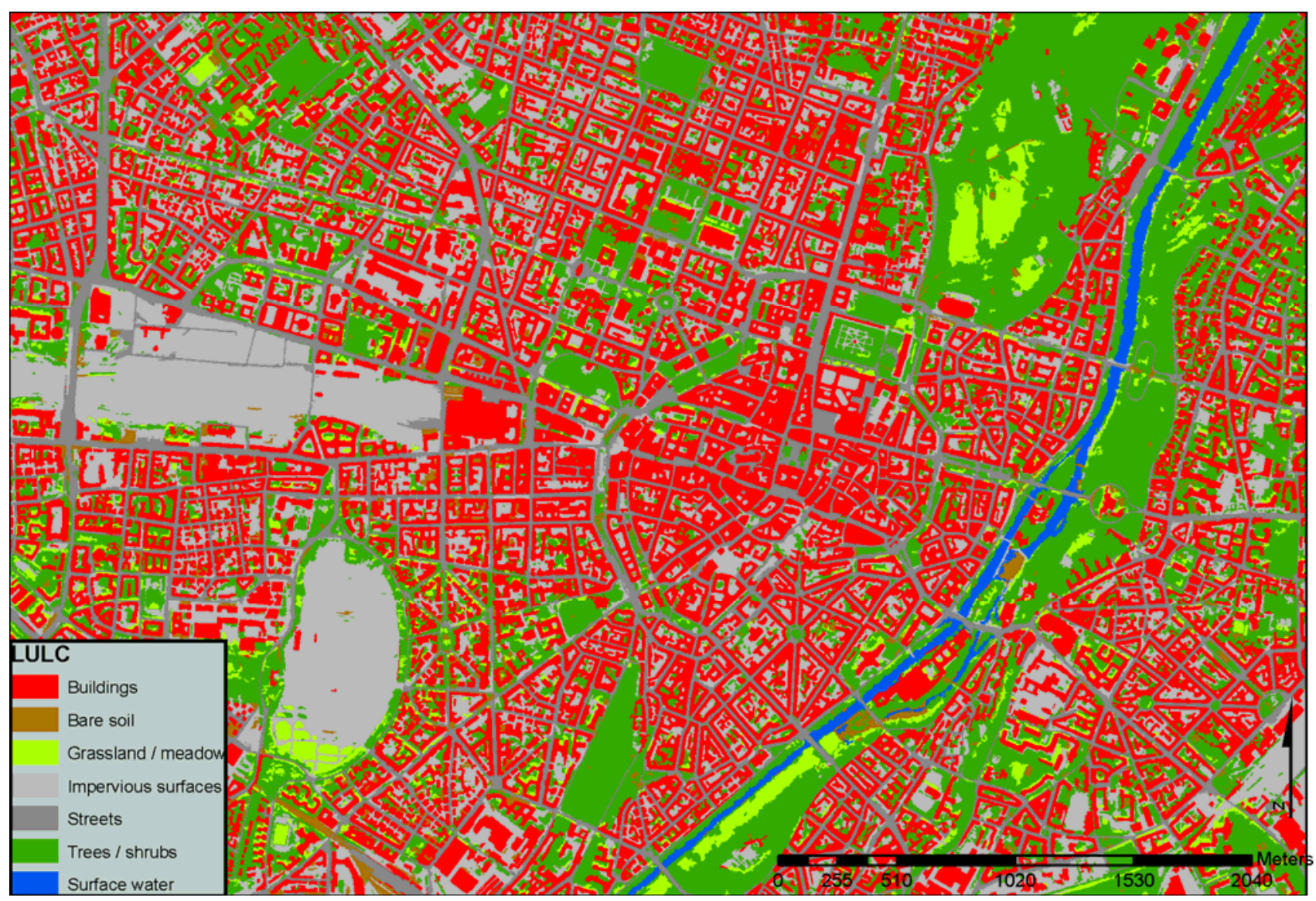

Figure 2. Result of the LULC classification for a subset of the city center of Munich.

\section{COMPARATIVE ANALYSIS OF URBAN STRUCTURES}

To explore the possibilities of describing distinct urban structure information by means of a detailed LULC classification a statistical approach is chosen. Therefore existing urban structure information from the UST classification is compared with the classification results. Besides the attributes of the class name of each individual urban structure type, the LULC classification comprises information about the block area, vegetation fraction, percentage of impervious surface, of builtup areas and of surface water. All these information is also covered by the automated classification of the remote sensing data sets. Hence, the areas for each LULC class are aggregated on the level of the building blocks which is the basic spatial unit for the comparison of the UST classification and the LULC classification. However, accuracy results of the LULC classification show high conformance with the UST classes, but as the focus of the comparative analysis is to find structural characteristics for housing construction classes, we selected only blocks belonging to one of the three superordinate classes ‘dense built-up’, ‘loose built-up’ and ‘industrial’ (Table 1). For the overlapping areas between the two data sets, a total of 7959 blocks were selected for further analysis.

\subsection{Thematic indicators: vegetation, impervious surfaces and built-up}

Thematic indicators based on the distinct land-cover and land-use classes are a valuable measure for urban planning. They are used for quantification of urban structure on the level of the building block [23]. In our study we want to find correlations between the thematic indicators and the various urban structure types. Thus, we compared the degree of accordance between the two classification results based on the thematic attributes provided by the UST classification and the aggregated percentage of each of the classes from the LULC classification. Figure 4 shows the relationship between 
the distinct fractional attribute of each individual block from the UST classification and the LULC classification. The correlation coefficients show high values for the relationships of each comparison: a): $c=0.85, b)$ : $c=0.85$ and $c$ ): $c=0.81$.

a)

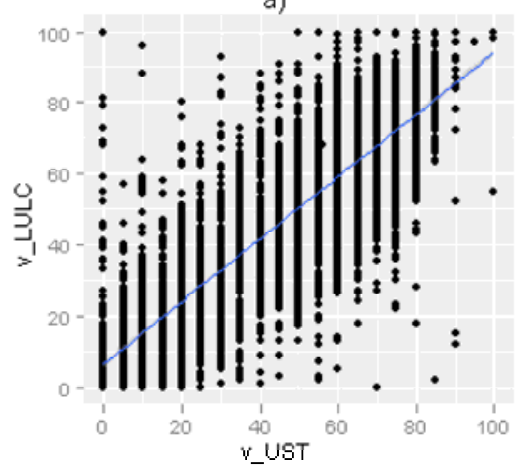

b)

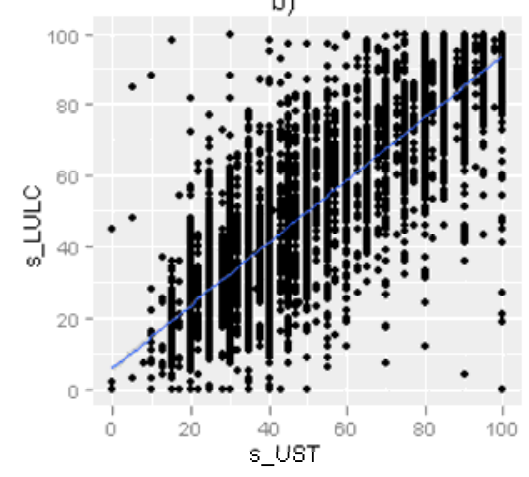

c)

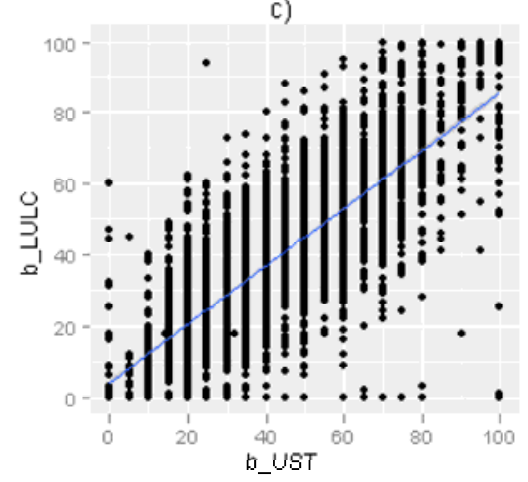

Figure 3. Scatterplots of the relationship between the percentage of vegetation fraction (a)), sealed area (b)) and built-up (c)) between the UST classification (x_UST) and LULC (x_LULC).

However, this general observation does not indicate the distribution of the shares of each of the fractions for each of the three built-up types. A much clearer picture about the distribution is given in figure 4, where the share of vegetated area (a-b), sealed area (c-d) and built-up area (e-f) is presented for both, the reference classification and the automated classification. The boxplots [24] show that the distribution of the vegetation fraction between the built-up types varies significantly between loose built-up blocks and denser or industrial built-up blocks. While the median for dense built-up blocks, represented by the horizontal line in the box, is $0.25 \%$, it is $0.65 \%$ for loose built-up blocks respectively (Figure 4a). A similar distribution of the values is identifiable for the results of the LULC classification (Figure 4b). The dots above and below the horizontal lines outside the box indicate outliers which are defined as values higher or lower the 1.5 times the interquartile range, which is the difference between the $75^{\text {th }}$ and $25^{\text {th }}$ percentile and is roughly 2 times the standard deviation. However, figure 5 shows that a general conformance between the reference classification and the LULC classification based on remote sensing data is visible for all three types of fractions.

\subsection{Geometric indicators based on area and height}

Figure 4 displays that only few thematic indicators enable objective differentiation between the individual blocks to some extent. However, the result of the LULC classification does not only list information about the share of varying land-cover and land-use types in terms of impervious surfaces, percentage of vegetated and built-up area. Structural information regarding the geometric indicators defining the individual built-up objects may be extracted as well. As mentioned above, for each individual classified building in the classification, the building height is available due to the information supplied by the DSM. Hence, additional indicators for the discrimination of various built-up types by means of remotely sensed data can be calculated. Besides the described indicators in figure 4, we derived the following geometric indicators presented in figure 5:

a) Sum area: Total built-up area for each block

b) Avg area: average area of individual buildings for each block

c) Sum volume: accumulated volume of all buildings for each block

d) Avg volume: average volume of individual buildings for each block

e) Avg height: average height of individual buildings for each block

f) Floor space index: this measure describes the ratio of the sum of all floor areas of every building to the total block area. 

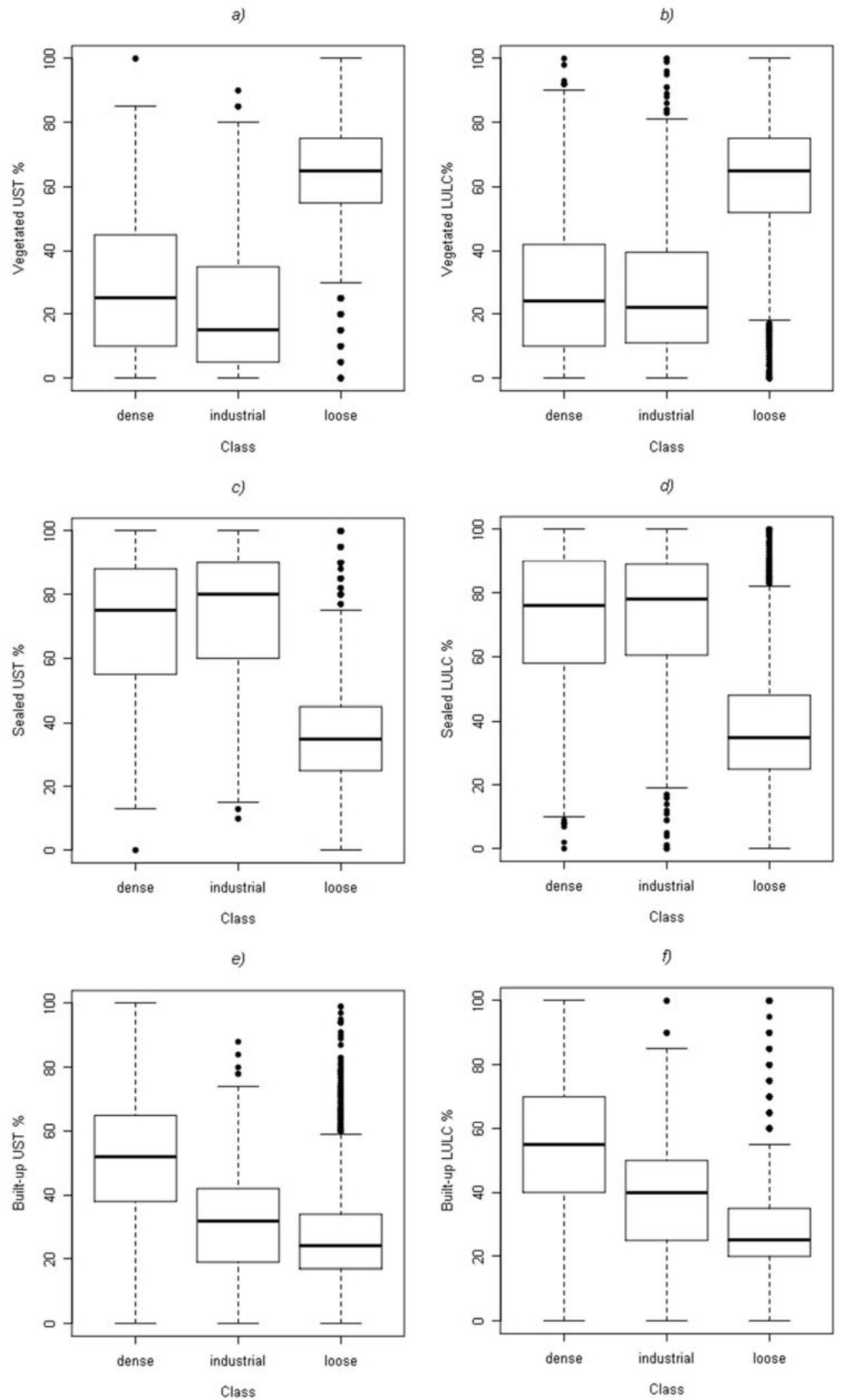

Figure 4. Percentage of vegetated (a-b), sealed (c-d) and built-up area (e-f) per block for the three built-up classes. 
As one can see from the plots in figure 5, some additional indicators for the discrimination of various built-up types can be sought by the integration of area and height values of the buildings. Especially indicators regarding the third dimension show a much clearer picture of possibilities to differentiate the distinct built-up types.

However, one goal of analyzing individual indicators derived by remote sensing data in terms of their potential to discriminate various types of built-up structures would be to reproduce the visual reference classification. For this purpose, we chose a statistical clustering algorithm to partition the data set into similar, meaningful clusters. The goal of cluster analysis is to find groups of similar objects within the data set that can be used for classification of the data [25]. We applied a standard K-means algorithm to retrieve three clusters out of the mentioned variables in figure 4 and figure 5. The results of the clustering algorithm are displayed in figure 6 (right) and for comparison, the UST classification is displayed on the left. The plot displays the general picture of dense built-up areas in or around the city center. This phenomenon is visible in both classifications. Interestingly, the industrial built-up 'belt' around the densely built-up areas in the center of Munich is visible in both images as well. Nevertheless, the number of blocks classified as 'industrial' is significantly higher in the automatically derived classification. However, in total, $41.6 \%$ of the blocks have been identified correctly by the clustering method.

a)

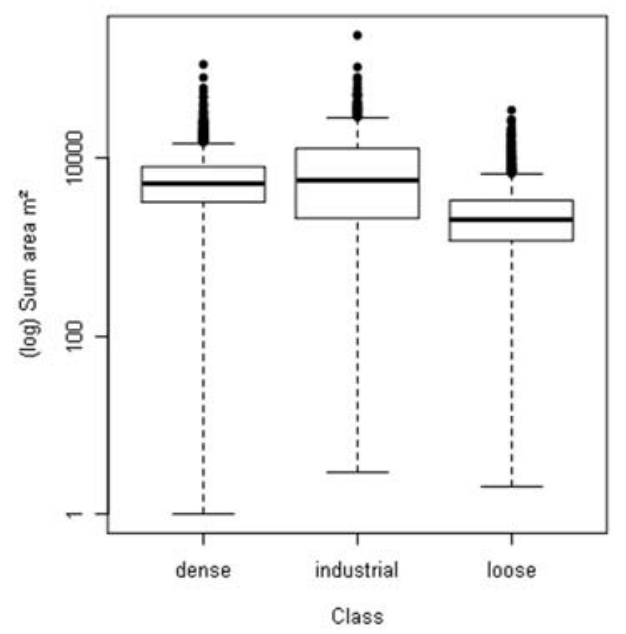

c)

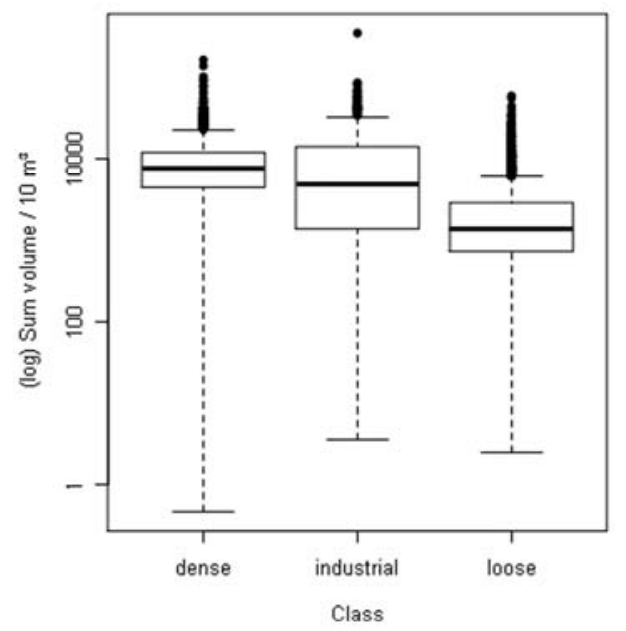

b)

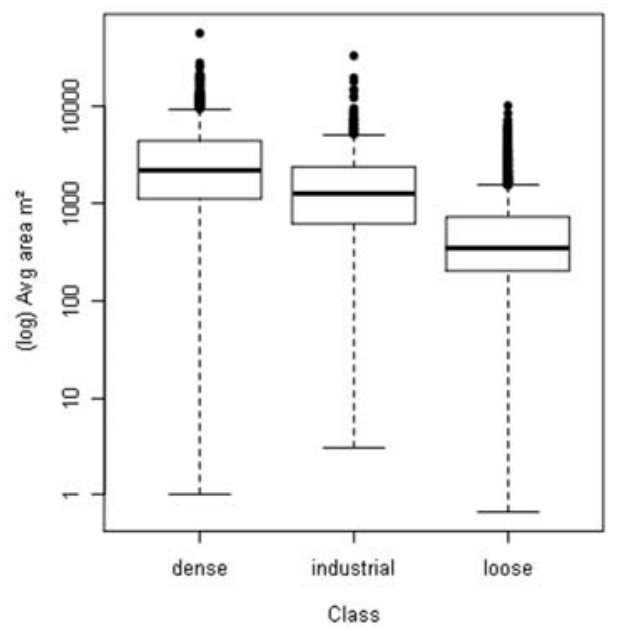

d)

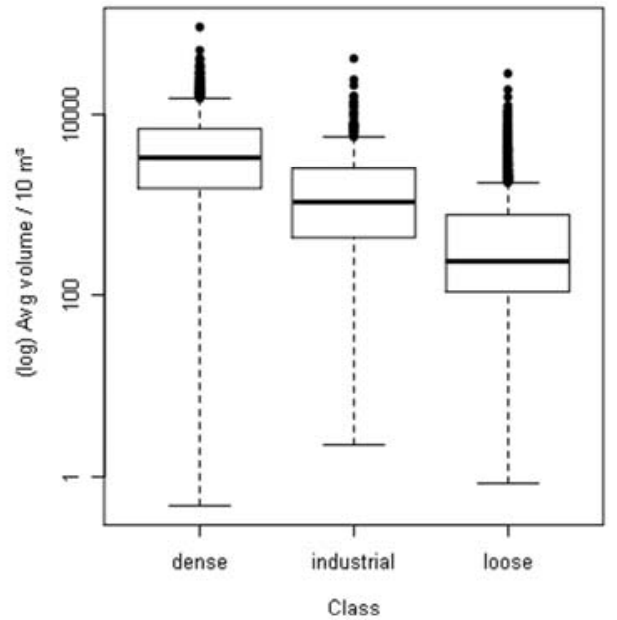


e)

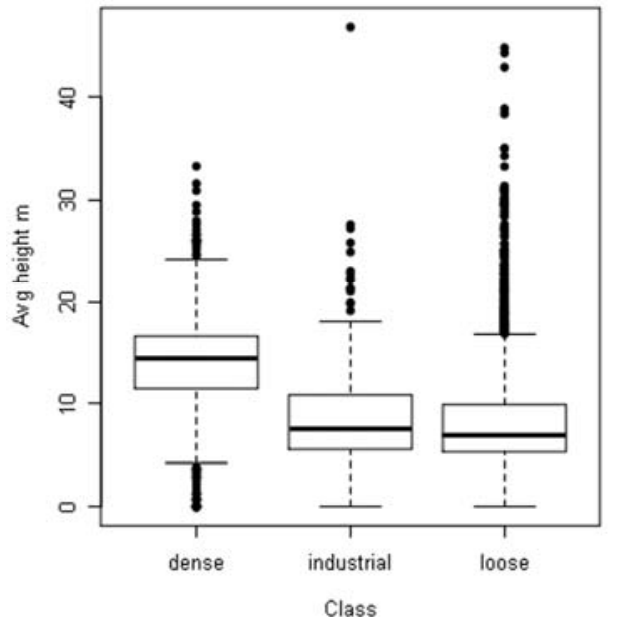

f)

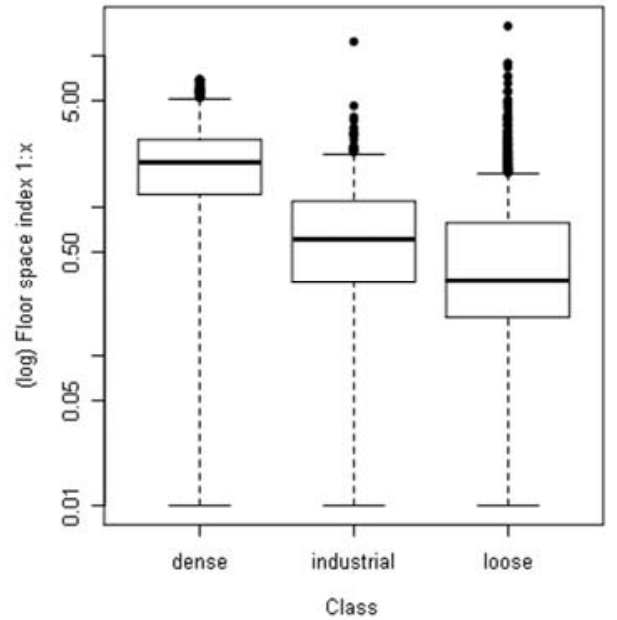

Figure 5. Distribution of geometric indicators for each of the built-up classes

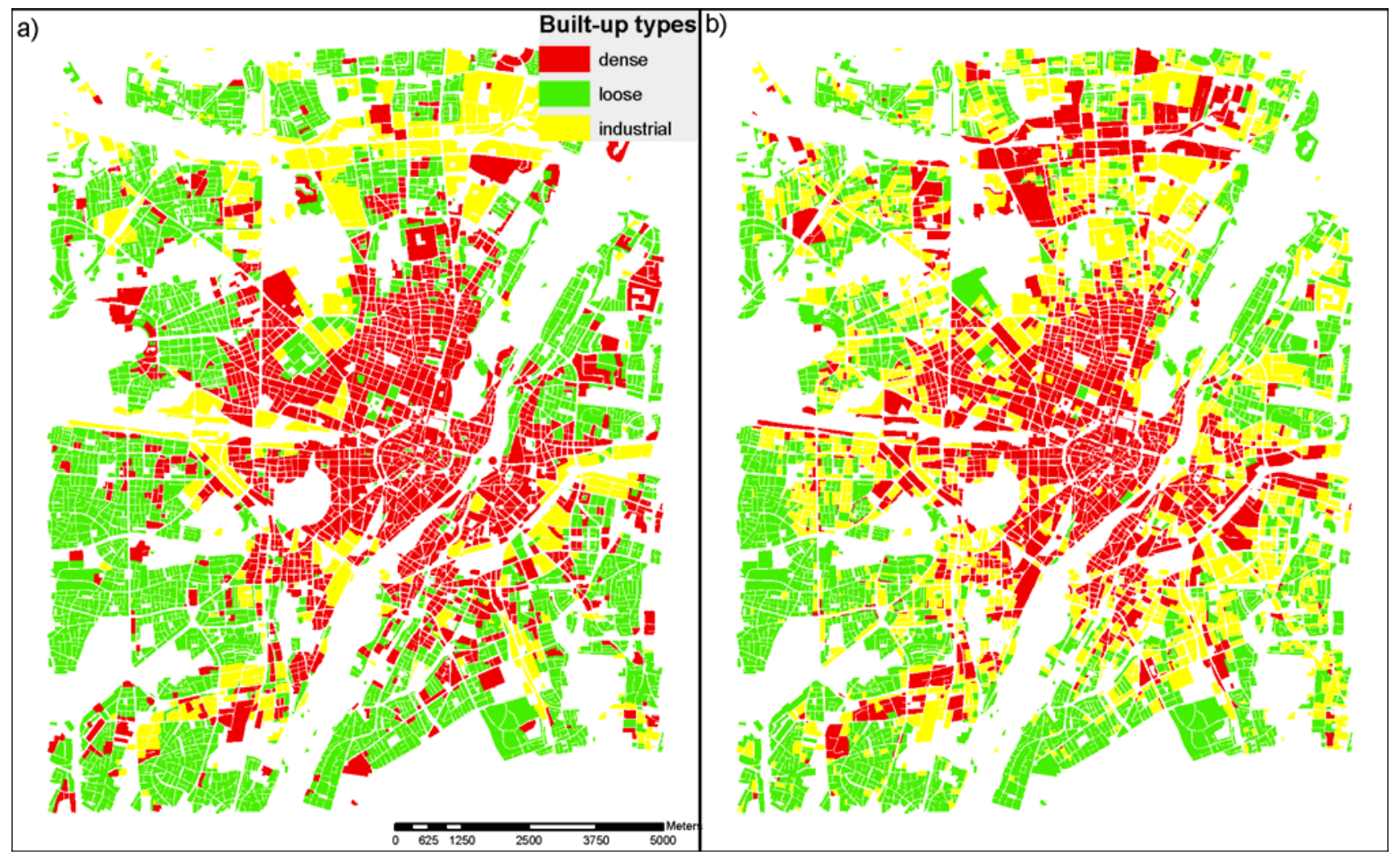

Figure 6. a) Reference classification [6] b) Classification of built-up types by k-Means cluster analysis.

\section{SUMMARY AND CONCLUSIONS}

In this study we show the possibility of deriving valuable urban structure information on the level of the building blocks. We extract the relevant information by means of object-based image analysis from remotely sensed imagery. As a result 
of this detailed land-use / land-cover information we obtain seven individual classes for the LULC and heights for each of the individual buildings. The aim of the study was to find relevant structural information based on this LULC classification for the identification of different urban structure types for the city of Munich. In a first step, we compared the structural information from the LULC classification with a manually derived urban structure types classification (UST). High accuracies of the LULC classification and high correlations of the structural information proof that it is possible to distinguish various urban structures on the level of the building block based on object-based image classification results.

\section{ACKNOWLEDGEMENTS}

This work was funded by the German Federal Ministry of Education and Research (BMBF) for the study 'Feasibilityund Planungs-Studie zur grundlegenden Verbesserung und Erweiterung der Längschnitts-Infrastrukturstudie "Soziooekonomisches Panel (SOEP)'”' (promotional reference: 01UW0706). The authors would like to thank the city of Munich for providing the reference classification of the urban structure types (Landeshauptstadt München, Kommunalreferat - Städtisches Vermessungsamt, Referat für Gesundheit und Umwelt, Stadt München).

\section{REFERENCES}

[1] Anas, A., Arnott, R. and Small, K. A., “Urban spatial structure,” Journal of Economic Literature, 36 (3), 1426-1464 (1998).

[2] United Nations, “World urbanization prospects: The 2007 revision,” New York: United Nations (2007).

[3] De Paul, O. V., "Remote Sensing: New applications for urban areas,” Proceedings of the IEEE, 95 (12), 2267-2268 (2007).

[4] Maktav, D., Erbek, F. S. and Jürgens, C., "Remote Sensing of urban areas,“ International Journal of Remote Sensing, 26 (4), 6z55-659 (2005).

[5] Donnay, J.-P., Barnsley, M. J. and Longley, P. A., “Remote Sensing and urban analysis,” In: Donnay, J.P., Barsley, M. J. and Longley, P. A., eds. [Remote Sensing and urban analysis], Taylor \& Francis, London, 3-10 (2001).

[6] Landeshauptstadt München, Kommunalreferat - Städtisches Vermessungsamt, Referat für Gesundheit und Umwelt, (2010).

[7] Pauleit, S., "Das Umweltwirkgefüge städtischer Siedlungsstrukturen: Darstellung des städtischen Ökosystems durch eine Strukturtypenkartierung zur Bestimmung von Umweltqualitätszielen für die Stadtplanung,“ PhD Thesis, Technische Universität of München (1998).

[8] Socher, W., "Umweltatlas Dresden. Karte 1.4. Stadtstrukturtypen,” (1999) http://www.dresden.de/media/pdf/infoblaetter/ua_1_4_text.pdf

[9] Banzhaf, E. and Höfer, R., "Monitoring urban structure types as spatial indicators with CIR aerial photographs for a more effective urban environmental management,” IEEE Transactions on Geoscience and Remote Sensing 1(2), 129-138 (2008).

[10] Breuste, J., Wächter, M. and Bauer, B.(eds.), “Beiträge zur umwelt- und sozialverträglichen Entwicklung von Stadtregionen,“ CD-ROM, UFZ-Umweltforschungszentrum Leipzig-Halle (2001).

[11] Sukopp, H., Kunick, W. and Schneider, C., "Biotopkartierung im besiedelten Bereich von Berlin (West): Teil II: Zur Methodik von Geländearbeit,“ Garten und Landschaft 7, 565-569 (1980)

[12] Duhme, F. and Pauleit, S., “Strukturtypenkartierung als Instrument der räumlich-integrativen Analyse und Bewertung der Umweltbedingungen in München,“ (1992).

[13] Müller, E., “Berlin-Zehlendorf. Versuch einer Kulturlandschaftsgliederung,“ PhD Thesis, Freie Universität Berlin (1965).

[14]Zierdt, M. and Dippmann, S., “Ökologische Stadtstrukturen und Lufthygiene im Stadtgebiet von Halle,“ Schriftenreihe der Gesellschaft für Deutschlandforschung, 46, 143-160 (1995).

[15] Senatsverwaltung für Stadtentwicklung, "Digitaler Umweltatlas Berlin. Stadtstruktur,“ www.stadtentwicklung.berlin.de/umwelt/umweltatlas/index.shtml

[16] Bochow, M., “Automatisierungspotenzial von Stadtbiotopkartierungen durch Methoden der Fernerkundung,” PhD Thesis, Universität Osnabrück (2010). 
[17] GeoEye, “GeoEye product guide v1.0.1,“ (2010)

http://geoeye.com/CorpSite/assets/docs/brochures/GeoEye_Product_Gzude.pdf

[18] Scholten, F., Gwinner, K., Tauch, R. and Boulgakova, O. "HRSC-AX - High-resolution orthoimages and digital surface models for urban regions,“ Proc. URBAN 2003, 225-229 (2003).

[19] Fischer, H. S., "Flächencharakterisierung der im Rahmen der Stadtbiotopkartierung erfassten Struktureinheiten,“ Ifanos Landschaftsökologie, im Auftrag der Landeshauptstadt München (2002).

[20] Wurm, M., Taubenböck, H., Roth, A. and Dech, S., "Urban structuring using multisensoral remote sensing data,” Proc. 2009 Urban Remote Sensing Joint Event (2009)

[21] Esch, T., Thiel, M., Bock, M. and Dech, S., "Improvement of image segmentation accuracy based on multi-scale optimization procedure,” IEEE Geoscience and Remote Sensing Letters, 5(3), 463-467 (2008).

[22] Taubenböck, H., Esch, T., Wurm, M., Roth, A. and Dech, S., “Object based feature extraction using high spatial resolution satellite data of urban areas,“ Journal of Spatial Science, 55(1), 111-126 (2010).

[23] Taubenböck, H., Heldens, W., Heiden, U. and Wurm, M., "Physische Indikatoren für die Stadtplanung,“ In: Taubenböck, H. and Dech, S. [Fernerkundung im urbanen Raum], (2010)

[24] McGill, R., Tukey, J. W. and Larsen, W. A., "Variations of Box Plots," The American Statistician 32(1), 12-16 (1978).

[25] Kumar, V., Steinbach, M. and Tan, P.-N., [Introduction to data mining], Addison Wesley, 487-568 p (2005). 